\title{
Maternal Lifestyle and Behavioral Factors Affect Risk of Spontaneous Preterm Birth
}

\author{
Sabah Lotfy Mohamed El Sayed*, Hanan Abd Mohdy Mohamed \\ Department of Obstetrics \& Gynecology Nursing, Faculty of Nursing, Zagazig University, Zagazig, Egypt \\ Email address: \\ sl_200878@yahoo.com (S. L. M. El Sayed) \\ ${ }^{*}$ Corresponding author
}

To cite this article:

Sabah Lotfy Mohamed El Sayed, Hanan Abd Mohdy Mohamed. Maternal Lifestyle and Behavioral Factors Affect Risk of Spontaneous Preterm Birth. American Journal of Nursing Science. Vol. 8, No. 3, 2019, pp. 109-118. doi: 10.11648/j.ajns.20190803.16

Received: March 12, 2019; Accepted: April 12, 2019; Published: May 23, 2019

\begin{abstract}
Aim of study: The study was carried out to evaluate maternal lifestyle and behavioral factors affecting the risk of spontaneous PTB. Methods: A descriptive study design was done in the postnatal ward of the Obstetrics Department at Zagazig University Hospital, Zagazig City, Al Sharkia Governorate. The sample of 200 women was assigned to two groups selected through the purposive sampling method from January to September 2017. The questionnaire was designed to collect background data of women. Also, lifestyle and behavioral features of women during pregnancy period. Results: The results of the current study showed that, there were no statistically significant differences between the two groups according to their socio-demographic characteristics group $(\mathrm{P}>0.05)$. However, there was a significant relation between spontaneous preterm birth and inadequate antenatal care, short inter-pregnancy interval, and lifestyle factors $(\mathrm{P}<0.001)$. Moreover, serious life events and vital exhaustion during their pregnancy were significant risk factors for spontaneous preterm birth. Conclusion: There is a statistically significant relationship between inter-pregnancy intervals (less than 12 months) and increased risk of spontaneous PTB. As well as, stresses of heavy and night working associated with the risk of PTB. Serious lifestyle events for pregnant women contribute to a significant increase in the risk of PTB, where Short sleep duration or prolonged, and vital exhaustion were highly associated with an increased risk of spontaneous PTB.
\end{abstract}

Keywords: Spontaneous Preterm Birth, Sleep Duration, Exhaustion

\section{Introduction}

Preterm birth (PTB) is defined as delivery which is completed a period of greater 20 and less than 37 weeks of gestation, which remains a major obstetric healthcare problem of global significance [1]. PTB is the major cause of death and disability in children up to 5 years of age and perinatal morbidity and mortality in the developed world; it represents about 15 million from all over the world, and one million of these babies die [2]. Approximately $85 \%$ of this burden was concentrated in Africa and Asia, where 10.9 million births were preterm. Almost, 0.5 million preterm births occurred in Europe and the same number in North America, while 0.9 million associated happened in the Caribbean and Latin America [3].

PTB babies are significantly in greater risk of perinatal problems [4]. Many babies born preterm suffer from health problems and lifelong disability. This greatly affects individuals, families, society and costs with perinatal health care, lifelong disability, and medical problems [5]. Cnattingius et al. (2013) who mentioned that hereditary qualities, life factors, (for example, diet, physical activity), and psychological variables considered hazard factors [6]. Goldenberg et al. (2012) reported that factors assumed to affect the danger of PTB which is related by bad lifestyle and behavior [7]. A variety of predisposing factors examined include lack of or delayed prenatal care, experiencing a short interval between pregnancies, exposure to socio-environmental stressors such as poverty, food insecurity, or violence [8].

The lifestyle and behavior indicate a complex mix of environmental exposures (eg, air contamination or specific food nutrients), as well as many life situations (tension, hard work, permanent work) and routines [9]. As is the case for most healthcare problems, prevention is better than cure [10]. Successful prevention of PTB requires a multifaceted approach, combining public health and educational programs, lifestyle 
modification, optimization of obstetric healthcare, effective prediction and diagnostic modalities, and the application of effective, targeted interventions [11]. Pre-pregnancy interferences e.g., weight control, nutritional supplement, and medically managing have a potential impact on rates of PTB although implementation and access remain significant barriers $[12,13]$.

\section{Significance of the study}

Preterm delivery is the chief problem in obstetrics, approximately $10 \%$ of all births are preterm [14]. Unfortunately, there are currently no effective diagnostic measures for preterm labor resulting in preterm birth and no effective early interventions for prevention, but some preventive measures play an important role, where raising socioeconomic standards with proper medical care of pregnant women including proper nutrition, health education are of utmost importance [15]. Maternal lifestyle and behavioral factors for spontaneous preterm births have not been evaluated in Zagazig, so this study was achieved.

Aim of the study

The study was conducted to assess maternal lifestyle and behavioral factors affecting the risk spontaneous preterm birth.

Research questions:

1. What is the maternal lifestyle factors affecting risk of spontaneous preterm birth?

2. What is the behavioral factors affecting risk of spontaneous preterm birth?

3. Operational definitions:

4. Term group was defined as women who were delivered of a live singleton infant between 37 and 40 weeks of gestation by spontaneous labor or rupture of membranes without induction or elective cesarean birth for maternal or fetal indications.

5. Preterm group was defined as women who were delivered a live singleton infant at less than 37 weeks of gestation by spontaneous labor or rupture of the membranes without induction or elective cesarean birth for maternal or fetal indications.

6. Antenatal visiting: According to the "Routine for maternal health care", promulgated by the Ministry of Health in 2011, antenatal visiting should be $\geq 5$ times (http://www.nhfpc.gov.cn/).

7. Interpregnancy intervals (IPI) were calculated as the time between the outcome of the previous pregnancy that ended either in a pregnancy loss or live birth and the last conception. It was categorized as two categories: $\leq 12$ months, and $>12$ months.

8. Family income/month: According to the report from women, and it was including 2 categorized adequate or inadequate.

9. Life stress was defined as negative life experience during pregnancy such as unemployment, death of relatives, and accidents.

\section{Subjects \& Methods}

Study design:
A descriptive design was used in this study.

Study setting:

The study was accomplished in the postnatal unit at the department of Obstetrics at Zagazig University Hospitals.

Sample type:

A purposive sampling was chosen according to certain criteria.

Sample size:

The sample size contained 200 women. It included 100 preterm group and 100 term groups. It was calculated using the following formula:

Sample size:

The total sample size was consisted of 200 mothers. It included 100 preterm group and 100 term groups. It was calculated using the following formula:

$$
\mathrm{n}=(1-\mathrm{P}) \times \mathrm{P} \times \frac{\mathrm{Z}^{2}}{\mathrm{D}^{2}}
$$

Where:

1. $\mathrm{N}=$ Sample size

2. $Z=$ The standard error of the mean corresponding to $95 \%$ confidence interval, which is 1.96

3. $\mathrm{P}=$ The incidence of preterm delivery, which is $13 \%$

4. $\mathrm{D}=$ The absolute precision which is $5 \%(0.05)$

5. $\mathrm{N}=1.96^{2} * 0.13 * 0.87 / 0.05^{2}=160.6823$

6. $N=160$ by increasing this figure by $20 \%$ for nonresponse $\mathrm{N}=180$

Sample of the study:

All women who attend to the postpartum care unit with the following criteria:

The criteria of the preterm group were: Women who were delivered a singleton preterm baby (28-<37 weeks of gestation) by vaginally or cesarean as a result of spontaneous idiopathic preterm labor with intact membranes, and have not medical or obstetric problems. The criteria of the term group were: Women who were delivered a full-term baby (37-42 weeks of gestation) spontaneously, uncomplicated birth of a singleton or an (elective) uncomplicated caesarean section.

Tools of data collection:

A questionnaire was designed by the researchers in light of relevant literature and the different studies. Two tools were used by the researcher to obtain the following

Part (I): An interview questionnaire sheet. It was composed of the following:

1. Women Socio-demographic data. As age, educational status, place of residence, and family income.

2. Menstrual history. The date of the last menstrual period was used to define gestational age and was confirmed by an ultrasound examination for weeks of gestation.

3. Obstetric history. A history of preterm delivery or abortion, antenatal care visits. The antenatal information was collected by, "How many times have you visited the health care or ANC service?. Also, "When was the last visit to health care or ANC service?" To determine the number of ANC visits before the third trimester. The visits were classified as visits $\leq 4$ times (inadequate) and visits $\geq 5$ times (adequate) and interpregnancy interval [16]. 
4. Medical history. A history of drug use and pre-existing medical conditions, such as hypertension and diabetes mellitus.

Part (II): Maternal lifestyle and behavioral assessment questionnaire:

1. Lifestyle factors that contribute to spontaneous preterm birth; type of work, working hours ( $>40$ hours/week vs. less), long times who spent standing ( $>6$ hours/day vs. less), daily workload (daily work hours during pregnancy; $>8$ hours/day vs. less), and shift work (Yes vs. No) [17].

2. Exposure to serious life events during current pregnancy. It was determined by the woman responses to the questions: "Over the past months of pregnancy, did any of the following life events occur?" e.g., financial trouble, an argument with husband (verbally or physically), and stress.

3. Dietary intakes. The verified food frequency questionnaire (FFQ) was used to obtain maternal dietary intake data one month prior to delivery. It was included 34 foods that represent the most common foods in the diet. The food items can be divided into 17 food groups, these were, grains, potatoes, vegetables, fruits, red meats, poultry, animal organs, aquatic products, eggs, dairy products, beans and bean products, nuts, oils, salt, water, beverage, snacks. Participants' food consumption were recorded in a day, a week or a month. Quantities were assessed using household measurements such as standard sized bowls and teaspoons. The information provided was added together to calculate participants' total daily (or weekly) food intake [18].

4. Antenatal vitamin supplements. These categories represent all possible combinations of multivitamin intake before and during pregnancy. Information was obtained from the medical record and women interview [19].

5. Sleep Patterns (hours / night). Sleeping duration less than or from 7 to 8 hours / night was an was an indication of poor sleep quality or abnormal sleep [20]. Participants were classified into three groups based on short $(\leq 6$ hours), normal (7-8 hours), and long ( $\geq 9$ hours) sleep duration. These categorizations were decided upon a priori, based on previously reported cut-points used by the investigators, who focused on sleep problems among pregnant women [21].

6. Maternal report of vital exhaustion in early pregnancy. It was assessed by asking the woman: "how often did she feel exhausted (except after exercise)?" Response choices were: (1) No, (2) Yes [1-3 times per month; 4 times per month or week; and day] [22].

Method

1. The agreement of the Morals Committee of the Faculty of Nursing and Supervisors of Hospital was obtained to manner the study and data collection.

2. All the voluntary participants were knowledgeable of the study objectivnes, and they are allowed to be withdrawn from the study at any time without giving any reason.

3. The validity of the tools was tested by three experts in the field of obstetrics and gynaecology nursing. They reviewed tools for clarity, relevance and accuracy. Alterations have been done according to their points of view.

4. The reliability of the questionnaire was checked using the Cronbach alpha coefficient (0.7) through the test and retesting method.

5. A pilot study was carried out on $10 \%$ (10 of the preterm group and 10 of the term group) in order to test the clarity and feasibility of the questionnaire. The sample of the pilot study was excluded from the main study sample. Based on the results of the pilot study, the required modifications were made prior to data collection.

6. The researchers visited the ward in the afternoon shift for two days per week. They presented themselves to all participants at the beginning of each visit. The time of interview with the participants the postpartum ward ranged from 20 to 30 for data collection.

7. Data were collected lasted for nine months from January until September 2017.

8. All data were entered into a computer using the Statistical Package for social Science (SPSS), version 19. Variables were compared numbers and percentage between two groups, and Chi square $\left(\chi^{2}\right)$ test was used as a test of significance. Also, the t-test was used to determine the difference between the mean of women age. Statistical level of significance was considered at $\mathrm{P}$-value $<0.05$.

\section{Results}

Table 1. Distribution of the studied groups according to their socio-demographic characteristics.

\begin{tabular}{|c|c|c|c|c|c|c|}
\hline \multirow{2}{*}{ Items } & \multicolumn{2}{|c|}{ Term group $(n=100)$} & \multicolumn{2}{|c|}{ Preterm group $(n=100)$} & \multirow{2}{*}{ Test } & \multirow{2}{*}{ P-value } \\
\hline & No & $\%$ & No & $\%$ & & \\
\hline \multicolumn{7}{|l|}{ Age (years) } \\
\hline$<20$ & 3 & 3.0 & 5 & 5.0 & \multirow{5}{*}{0.64} & \multirow{5}{*}{0.88} \\
\hline $20-<30$ & 47 & 47.0 & 46 & 46.0 & & \\
\hline $30-<35$ & 45 & 45.0 & 43 & 43.0 & & \\
\hline$\geq 35$ & 5 & 5.0 & 6 & 6.0 & & \\
\hline Mean \pm SD & \multicolumn{2}{|c|}{$30.62 \pm 5.07$} & \multicolumn{2}{|c|}{$30.93 \pm 5.93$} & & \\
\hline Illiterate & 11 & 11.0 & 5 & 5.0 & \multirow{5}{*}{4.02} & \multirow{5}{*}{0.25} \\
\hline Primary school & 10 & 10.0 & 15 & 15.0 & & \\
\hline Secondary school & 36 & 36.0 & 42 & 42.0 & & \\
\hline College graduate & 43 & 43.0 & 38 & 38.0 & & \\
\hline Place of residence & & & & & & \\
\hline
\end{tabular}




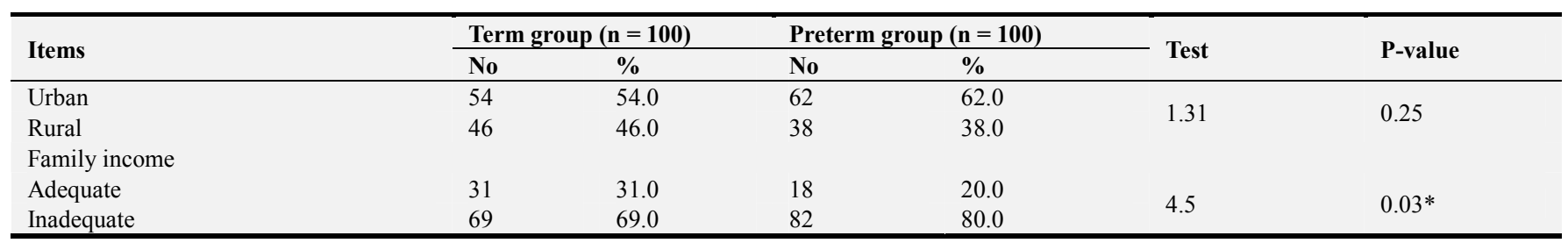

* Statistically significant $(\mathrm{P}<0.05)$.

Table 1 Shows the distribution of the studied groups according to their socio-demographic characteristics. It was realized that, there were no statistically significant differences between the two groups regarding age, educational level, and place of residence $(\mathrm{P}>0.05)$. The mean age of preterm group was $30.93 \pm 5.93$ years, while for the term groups it was $30.62 \pm$ 5.07 years. The most common of participants $(47.0 \%$ of preterm group \& $46.0 \%$ of term) were aged $20-<30$ years, followed by the age group $30-<35$ years $(45.0 \%$ of preterm group \& $43.0 \%$ of term group). There was no remarkable difference between two groups $(\mathrm{t}=0.64 ; \mathrm{P}=0.88)$.

As regards level of education, $38.0 \%$ of preterm group and $43.0 \%$ of term groups were college graduate, $42.0 \%$ of preterm group and $36.0 \%$ term group had a secondary level. In relation to place of residence, $62.0 \%$ of preterm group and $54.0 \%$ of term groups were from urban areas, while $38.0 \%$ and $46.0 \%$ respectively were from rural areas. Notably, the family income was significantly linked with the risk of spontaneous PTB $\left(\mathrm{X}^{2}=\right.$ $6.13, \mathrm{P}=0.03)$.

Table 2. Distribution of the studied groups according to their obstetric history.

\begin{tabular}{|c|c|c|c|c|c|c|}
\hline \multirow{2}{*}{ Items } & \multicolumn{2}{|c|}{ Term group $(n=100)$} & \multicolumn{2}{|c|}{ Preterm group $(n=100)$} & \multirow{2}{*}{ Test } & \multirow{2}{*}{ P-value } \\
\hline & No & $\%$ & No & $\%$ & & \\
\hline \multicolumn{7}{|l|}{ Parity } \\
\hline Nulliparous & 54 & 54.0 & 57 & 57.0 & \multirow{2}{*}{0.18} & \multirow{2}{*}{0.66} \\
\hline Multiparous & 46 & 46.0 & 43 & 43.0 & & \\
\hline \multicolumn{7}{|c|}{ Previous history of PTB } \\
\hline No & 78 & 78.0 & 72 & 72.0 & \multirow{2}{*}{0.96} & \multirow{2}{*}{0.32} \\
\hline Yes & 22 & 22.0 & 28 & 28.0 & & \\
\hline No & 79 & 79.0 & 81 & 81.0 & \multirow{2}{*}{0.12} & \multirow{2}{*}{0.72} \\
\hline Yes & 21 & 21.0 & 19 & 19.0 & & \\
\hline \multicolumn{7}{|c|}{ Antenatal care visits } \\
\hline Yes & 86 & 86.0 & 73 & 73.0 & \multirow{2}{*}{5.18} & \multirow{2}{*}{$0.02 *$} \\
\hline No & 14 & 14.0 & 27 & 27.0 & & \\
\hline \multicolumn{7}{|c|}{ Adequacy number of antenatal care visits } \\
\hline Adequate $(\geq 5)$ & 76 & 76.0 & 48 & 48.0 & 16.6 & $<0.00004^{* *}$ \\
\hline \multicolumn{7}{|c|}{ Inter-pregnancy interval (month) } \\
\hline$\leq 12$ & 33 & 33.0 & 52 & 52.0 & \multirow{2}{*}{7.3} & \multirow{2}{*}{$0.006^{*}$} \\
\hline$>12$ & 67 & 67.0 & 48 & 48.0 & & \\
\hline
\end{tabular}

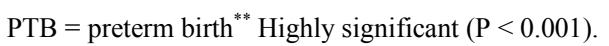

As shown in table 2, parity, previous history of PTB and abortion were insignificant factors for PTB. Conversely, women who gave birth to preterm babies were more likely to report that they didn't receive antenatal care $(27.0 \%$ versus $14.0 \%)$ linked to women who delivered at term. There was a noteworthy relation between PTB and prenatal care visits $\left(\mathrm{X}^{2}=5.18, \mathrm{P}=\right.$ $0.02)$.

Concerning the visiting numbers of prenatal care, the percent in preterm group was $\geq 5$ times $(48.0 \%)$, and $<5$ times $(52.0 \%)$ while, in the term group, the percent of $\geq 5$ times and $<5$ times were $76.0 \%$ and $24.0 \%$, respectively. However, there was a high significantly difference between the two groups $\left(\mathrm{X}^{2}=16.6, \mathrm{P}<\right.$ $0.00004)$. Moreover, the inter-pregnancy interval $\leq 12$ months was higher in the preterm group than term group $(52.0 \%$ versus $33.0 \%)$. There was statistically significant difference $\left(\mathrm{X}^{2}=7.3\right.$, $\mathrm{P}=0.006)$.

Table 3. Distribution of the studied groups as indicated by their way of life factors.

\begin{tabular}{|c|c|c|c|c|c|c|}
\hline \multirow{2}{*}{ Items } & \multicolumn{2}{|c|}{ Term group $(n=100)$} & \multicolumn{2}{|c|}{ Preterm group $(n=100)$} & \multirow{2}{*}{ Test } & \multirow{2}{*}{ P-value } \\
\hline & No & $\%$ & No & $\%$ & & \\
\hline \multicolumn{7}{|l|}{ Type of work } \\
\hline Housewife & 41 & 41.0 & 29 & 29.0 & & \\
\hline Agriculturalists & 29 & 29.0 & 39 & 39.0 & & \\
\hline Commercial service staffs & 7 & 7.0 & 16 & 16.0 & 16.2 & $0.002^{*}$ \\
\hline Professional staffs & 8 & 8.0 & 13 & 13.0 & & \\
\hline Government staffs & 15 & 15.0 & 3 & 3.0 & & \\
\hline \multicolumn{7}{|l|}{ Working hours / week } \\
\hline$\leq 40$ & 27 & 27.0 & 14 & 14.0 & 5.18 & $0.02^{*}$ \\
\hline
\end{tabular}




\begin{tabular}{|c|c|c|c|c|c|c|}
\hline \multirow{2}{*}{ Items } & \multicolumn{2}{|c|}{ Term group $(n=100)$} & \multicolumn{2}{|c|}{ Preterm group $(\mathrm{n}=\mathbf{1 0 0})$} & \multirow{2}{*}{ Test } & \multirow{2}{*}{ P-value } \\
\hline & No & $\%$ & No & $\%$ & & \\
\hline$>40$ & 73 & 73.0 & 86 & 86.0 & & \\
\hline \multicolumn{7}{|c|}{ Standing work (hours/day) } \\
\hline $\begin{array}{l}\leq 6 \\
>6\end{array}$ & $\begin{array}{l}40 \\
60\end{array}$ & $\begin{array}{l}40.0 \\
60.0\end{array}$ & $\begin{array}{l}25 \\
75\end{array}$ & $\begin{array}{l}25.0 \\
75.0\end{array}$ & 5.12 & $0.02^{*}$ \\
\hline \multicolumn{7}{|c|}{ Daily workload (daily work hours during pregnancy) } \\
\hline $\begin{array}{l}\leq 8 \text { hours } \\
>8 \text { hours }\end{array}$ & $\begin{array}{l}68 \\
32\end{array}$ & $\begin{array}{l}68.0 \\
32.0\end{array}$ & $\begin{array}{l}47 \\
53\end{array}$ & $\begin{array}{l}47.0 \\
53.0\end{array}$ & \multirow[t]{2}{*}{4.72} & \multirow[t]{2}{*}{$0.03^{*}$} \\
\hline Shift work & & & & & & \\
\hline $\begin{array}{l}\text { No } \\
\text { Yes }\end{array}$ & $\begin{array}{l}66 \\
34\end{array}$ & $\begin{array}{l}66.0 \\
34.0\end{array}$ & $\begin{array}{l}22 \\
78\end{array}$ & $\begin{array}{l}22.0 \\
78.0\end{array}$ & 39.2 & $0.00^{* *}$ \\
\hline
\end{tabular}

Table 3 presents the lifestyle factors of the studied groups. Itreveals that, more than one third $39.0 \%$ of the preterm group was agriculturalists; followed by $29.0 \%$ were housewife. In the term group, $41.0 \%$ were housewife, while $29.0 \%$ were agriculturalist. There is a statistically difference between preterm case and group $\left(\chi^{2}=16.2, \mathrm{P}=0.002\right)$. The same table, working conditions during pregnancy includes; working hours and those working in a standing position for more than six hours a day have been identified as hazard factors of natural PTB. Likewise, long hours working women and shift work, also had a significantly higher hazard of PTB ( $\mathrm{P}=0.03 \& \mathrm{P}=0.00$, respectively).

Table 4. Distribution of the studied groups regardingtheir hazards life events during the pregnancy months.

\begin{tabular}{|c|c|c|c|c|c|c|}
\hline \multirow{2}{*}{ Items } & \multicolumn{2}{|c|}{ Term group $(n=100)$} & \multicolumn{2}{|c|}{ Preterm group $(\mathrm{n}=100)$} & \multirow[b]{2}{*}{ Test } & \multirow[b]{2}{*}{ P-value } \\
\hline & \begin{tabular}{|l|} 
No \\
\end{tabular} & $\%$ & No & $\%$ & & \\
\hline \multicolumn{7}{|c|}{ Financial trouble } \\
\hline No & 40 & 40.0 & 25 & $25.0 \%$ & \multirow{3}{*}{5.12} & \multirow{2}{*}{$0.02^{*}$} \\
\hline Yes & 60 & 60.0 & 75 & $75.0 \%$ & & \\
\hline \multicolumn{6}{|c|}{ Argument with Husband } & \\
\hline No & 67 & 67.0 & 49 & 49.0 & \multirow{3}{*}{6.6} & \multirow{2}{*}{$0.009^{*}$} \\
\hline Yes & 33 & 33.0 & 51 & 51.0 & & \\
\hline \multicolumn{6}{|l|}{ Stress } & \\
\hline No & 61 & 61.0 & 42 & 42.0 & 7.2 & $0.007^{*}$ \\
\hline Yes & 39 & 39.0 & 58 & 58.0 & & \\
\hline
\end{tabular}

Table 4 reveals that, financial trouble is the highest percentage $(75.0 \%)$ of the preterm group as compared $(60.0 \%)$ of term group. There was statistically difference between the two groups $\left(\mathrm{X}^{2}=5.12, \mathrm{P}=0.02\right)$. The prevalence of SPTB according to maternal exposure to an argument with husband during pregnancy was $33.0 \%$ for term group compared to $51.0 \%$ of preterm group $\left(\mathrm{X}^{2}=6.6, \mathrm{P}\right.$ $=0.009)$. Women exposed to stress during pregnancy had increased the risk of SPTB. There was statistically significant difference among the studied groups $\left(\mathrm{X}^{2}=7.2, \mathrm{P}=0.007\right)$.

Table 5. Distribution of the studied groups in relation to their behaviorfactors during months of pregnancy.

\begin{tabular}{|c|c|c|c|c|c|c|}
\hline \multirow{2}{*}{ Items } & \multicolumn{2}{|c|}{ Term group $(n=100)$} & \multicolumn{2}{|c|}{ Preterm group $(n=100)$} & \multirow{2}{*}{ Test } & \multirow{2}{*}{ P-value } \\
\hline & No & $\%$ & No & $\%$ & & \\
\hline \multicolumn{7}{|l|}{ Dietary Intake } \\
\hline Adequate intake & 12 & 12.0 & 25 & 25.0 & \multirow{2}{*}{5.6} & \multirow{2}{*}{$0.01 *$} \\
\hline Inadequate intake & 88 & 88.0 & 75 & 75.0 & & \\
\hline \multicolumn{7}{|c|}{ Antenatal vitamin supplements } \\
\hline Yes & 86 & 86.0 & 64 & 64.0 & \multirow{2}{*}{12.9} & \multirow{2}{*}{$0.0003^{* *}$} \\
\hline No & 14 & 14.0 & 36 & 36.0 & & \\
\hline$\leq 6$ hours & 26 & 26.0 & 57 & 57.0 & \multirow{3}{*}{39.3} & \multirow{3}{*}{$0.00 * *$} \\
\hline $7-8$ hours & 53 & 53.0 & 12 & 12.0 & & \\
\hline$\geq 9$ hours & 21 & 21.0 & 31 & 31.0 & & \\
\hline \multicolumn{7}{|c|}{ Complaints of vital exhaustion } \\
\hline No & 39 & 39.0 & 21 & 21.0 & \multirow{2}{*}{7.71} & \multirow{2}{*}{$0.005^{*}$} \\
\hline Yes & 61 & 61.0 & 79 & 79.0 & & \\
\hline \multicolumn{7}{|l|}{ Vital exhaustion } \\
\hline Daily & 3 & 3.0 & 21 & 21.0 & 16.4 & $0.0002 * *$ \\
\hline
\end{tabular}

Table 5, shows the distribution of the studied mothers according to their behavioral factors during months of pregnancy. It was noted that, healthy diet was in relation with a decreased hazard of spontaneous PTB. There was a statistically significance difference between preterm group and term group $\left(\mathrm{X}^{2}=5.6, \mathrm{P}=0.01\right)$. There was a major relation between women who didn't take vitamin supplements during pregnancy, with a higher prevalence of 
preterm group $(36.0 \%)$ than term groups $(14.0 \%)$ at $\mathrm{P}=$ 0.0003 .

With regard to the duration of sleep for less than 6 hours per night, Table 5 indicates that more than half $(57.0 \%)$ were preterm and a quarter $(26.0 \%)$ of the term group. Concerning the duration of sleep for more than 9 hours per night, $31.0 \%$ of the preterm group and $21.0 \%$ of the term group compared to those sleeping from 7 to 8 hours per night, with a significant relationship between sleep duration and PTB (X2 $=39.3, \mathrm{P}=0.005)$.

The same table found statistical differences between the frequency of vital exhaustion during the period of pregnancy and spontaneous premature birth $(\mathrm{P}=0.005 \& \mathrm{P}=0.0002)$.

\section{Discussion}

Worldwide the rates of PTB is $11.1 \%$, but varies with geography and race, ranging from $15 \%$ or more in some parts of Africa to $5-6 \%$ in several European nations and possibly lower in some parts of East Asia [23]. A center-based cross sectional study was conducted to detect the percentage and factors affecting preterm births in an area in South Cairo, through a secondary health care facility (Al-Moneera General Hospital, MOH). The study revealed that 41 deliveries $(8.2 \%)$ were preterm deliveries among all deliveries in the obstetric unit of the El Moneera general hospital during the period from July to December 2014 [24]. In addition to being the primary reason of newborn death, there is an increasing proof to show that preterm delivery is a opposing pregnancy result related with an increased hazard of future motherly cardiovascular health [25].

Socio-demographic features have been sought to clarify natural PTB and although do not necessarily imply causation. This study was consistent with a study done in Brazil, [26] they reported that socio-demographic characteristics of women were insignificantly associated with spontaneous preterm birth. So, identifying at-risk women will help initiate risk specific interventions.

The study revealed that women aged 40 years or older were preterm, while women between the ages of 30 and 34 were associated with the minimum risk of preterm birth with wasn't relationship between women age and natural PTB $(\mathrm{P}=0.88)$. Similarly, in Lombok, Indonesia, Sebayang et al. (2012) showed that maternal age was insignificantly associated with preterm birth [27]. But, a retrospective cohort study using data from the QUARISMA study, a large Canadian randomized group led the trial, which collected data from 184,000 births in 32 hospitals [28].

Level of education was not linked with natural preterm delivery in the current study. A study conducted in Nigeria, Oliver et al. (2012) reported that, contradictory results on the relation between mothers education and PTB [29]. This may be due to increased access to basic education among the mothers in this study whose background was mainly urban. In another study in Lombok, Indonesia, Sebayang et al. (2012) had shown that women with high school education had 36\% lower probabilities of having a PTB, compared with women with no primary education [27]. In contrast, a recent finding from Canada shown maternal level of education was found to be a risk factor for preterm delivery [30]. This can be clarified by differences in the socio-demographic factors among studies.

Low financial status is also theoretical to be an important danger factor for PTB. It is associated with unhealthy or risky behaviors, exposure to stress and psychological reactions that influence gestation negatively. The low economic status of women may lead to a lack of access to prenatal care at the beginning of pregnancy and have not received better care. Therefore, they may not be able to cope with complications related to pregnancy. A similar phenomenon was observed in Nova Scotia, Joseph et al. (2014) showed that the socioeconomic position was associated with spontaneous preterm birth, nonetheless with iatrogenic PTB [31]. This result was in contrast with Aragão et al. (2014) who found that family salary and household factors were not found to be important hazard factors for PTB [32]. The possible reason for this is that the study was conducted in public hospitals, where women belong to the same social and economic class. In addition, there are barriers to prenatal care for many low socioeconomic women, who are likely to be uninsured or have difficulty accessing health care.

This stud uncovered that the number of deliveries, abortions, and previous history of preterm delivery were uncorrelated to be hazard factors for natural PTB. A study conducted in Rafidia Hospital, Kingdom of Saudi Arabia, by Lutfi \& Ezat, (2015) their study results illustrated that the number of pregnancies, deliveries, and abortions hadn't relationship with PTB $(\mathrm{P}=0.246)$ [33]. Another study carried out by Victor et al. (2011) found no association between past history of PTBs and abortion and development of PTBs [34].

However, Ayman \& Abdelwahid, (2015) recognized that there is a significant association between preterm birth and previous preterm birth. The reasons for this finding could be explained as preterm birth was included besides the difference in the research population, and this may be due to the persistence of the same factor which led to that condition (e.g. hemorrhage or hypertension) [24].

Current research has shown a negative affiliation between antenatal care and PTB. Also, this study found that women who reported inadequate prenatal care were more likely to have a natural PTB. As the study was carried out by Abu Hamad et al. (2007), used two groups from 2 main governmental hospitals in the Gaza Strip, El-Shifa and Khan Younis hospitals. The danger of PTB increased 2.4-fold among those who attended $<4$ visits than those who attended 4 visits during the entire pregnancy period [35]. This confirms the importance of conducting population-oriented programs encouraging attendance at antenatal care, focusing on the importance of early attendance

In the USA, a study conducted by Chen et al. (2007) reported that teenage mothers are more likely to get inadequate prenatal care which has been strongly associated with PTB. Adolescents with good admission to health care 
often do not show a higher risk of complications. It is worth noting that sufficient, timely antenatal health care can be favorable in detecting and treatment of pregnancy complications, especially for the high-risk group [36]. More attention needs to be paid to the effectiveness and quality of each antenatal care visit, especially for women with hazard factors of PTB or other complications.

The current study results demonstrated there is a statistically relationship between inter-pregnancy intervals under one year and increased hazard of natural PTB $(\mathrm{P}=0.006)$. Similar results have been obtained in Al Ain, United Arab Emirates; by Al-Jasmi et al. (2002) who illustrated that short interpregnancy interval is a hazard factor for natural PTB [37]. As well, in Ohio, the northeastern US, DeFranco et al. (2014) demonstrated that women with a shorter period between pregnancies were more bound to give birth preceding 39 weeks of gestation compared to those who have sufficient birth period. Birth after the estimated due date (more than 40 weeks) occurred less often in women with short IPI of less than 12 months, $16.9 \%$ compared to $23.1 \%$ for a normal IPI. Short pregnancy interval certainly predisposes to PTBs as it leads to nutritional deficiency and incomplete return of normal maternal tissue [38]. This indicates the importance of conducting population-based programs about the importance of interval between pregnancies.

Concerning the relation between some lifestyle characteristics and risk of SPTBs, the results were obtained from the current study indicated that high working stresses (hard work, those who work long hours, and stand for long periods) and night work related with the hazard of PTB. Similar results were carried out by Takayama, et al. (2010) showed risk factors for PTB include: some lifestyle conditions, including standing work or strenuous work, and behaviors [39].

A study directed by Escribà-Aguir et al. (2001) in Spain showed that medium or high intensity physical workload (strenuous postures, load carrying, standing) increased the hazard of PTB [40]. This might be attributed to that stresses are associated with the release of stress hormones that may lead to preterm births. This study underlines that more attention should be given to women's working conditions during pregnancy, and effort should be intensified towards reducing exposure to long working hours for pregnant women.

The current study investigated the influence of several pregnancy-related maternal lifestyle factors on spontaneous preterm birth. The results showed serious lifestyle events of pregnant women contribute to a significant increase in the risk of PTB. Similarly, Traviss et al. (2013) found that women who were at risk of danger life events during pregnancy may affect the risk of PTB [41]. A research study was conducted in Sweden by Class et al. (2011) analyzed the relationship between stress and found that the risk of PTB was raised when occasion happened at the fifth and sixth month of pregnancy [42]. A prospective study in the People's Republic of China in 2008 assessed the effects of maternal exposure to life-threatening events (monetary, passionate, horrendous, and spousal-related occasions). Also, Zhu et al. (2010) reported the risk of PTB, was increasing numbers of life threating events during the first and second trimesters [43]. Thus, preconception counseling regarding stressful lifestyle should not be neglected.

Women's feeding during pregnancy assumes a vital value in giving the vital supplements to fetal development [44]. An inequity in motherly diet may be a key factor related with PTB [45]. In the current study, adequate women diet before and during pregnancy was important for the health of women and their growing fetus, while inadequate diet is related with a hazard of natural PTB, which was similar to another study in Beijing, a study was carried out by Zhang et al. (2012) on 1391 women with PTB group and 1391 women with term delivery group. They stated that enough diet is serious for fetal growth and lessen the hazard of preterm delivery [46]. Therefore, the current study suggests that health education measures should be taken to enhance the feed value of pregnant women, especially for women before pregnancy.

The current study finding showed that vitamin supplements had a vital value in lowering the hazard of PTB. The data from 6 trials of 1,687 ladies who got vitamin D supplements during pregnancy were less likely to be at risk of PTB than those got placebo therapy or routine prenatal care. De-Regil et al. (2016) found that ladies who received vitamin D and calcium complements had an increase hazard of PTB [47]. In southern China, a study conducted by showed that daily consumption of $400 \mu \mathrm{g}$ folic acid alone during the preconception period was linked with a reduction hazard of spontaneous PTB. Apparently, these agents inhibit production of proinflammatory cytokines [48].

Wagner et al. (2013) studied the effectiveness of vitamin D supplementation in dropping PTB hazard in 494 pregnant women at the medical university of South Carolina Charleston and observed similar results with the inverse relation between vitamin $\mathrm{D}$ supplementation and preterm birth [49]. Further, A systematic review of the evidence of the impact of maternal diet before and during early pregnancy on maternal, newborn and child health outcomes, Ramakrishnan et al. (2012) indicated that higher preconception multivitamin use was associated with a reduced risk of preterm birth [50].

According to women sleep duration and vital overtiredness in pregnancy, the current study results proposed that disorders induration of sleep ( $\leq 6$ or $\geq 9$ hours per night), and vital tiredness were highly associated with an increased the risk of spontaneous PTB. Good pattern of sleep during pregnancy is considered the most important predictor of pregnancy outcomes. Also, poor pattern of sleep can increase the incidence of PTB and newborn intensive care unit entrance, gestational hypertension, diabetes with pregnancy, and post-delivery misery [51].

These findings are congruent with study conducted at the Hospital Nacional DOS de Mayo, the Institution Nacional Materno Perinatal de Lima, and the Hospital Edgardo Rebagliati Martins in Lima, Peru, in 2009-2010 which examined the relationship between duration or period of 
women sleep and SPTB. In a study done by [52] suggested that short ( $\leq 6$ hours), and prolonged duration ( $\geq 9$ hours) of sleep, in addition any of vital tiredness were linked with all subtypes of spontaneous PTB. But, the association between sleep disorder and PTB was not moral as noticed by Dolatian et al. (2014) [53].

Furthermore, in Southern California, Guendelman et al. (2013) who found no link between sleep duration (either sufficient or insufficient) and preterm delivery [20]. The differences may be because the previous study did not allocate a type of premature birth, while the current study focused on risk factors for spontaneous early birth. This requires increased attention to develop strategies to reduce the risk of premature birth.

\section{Conclusion}

The Periods between pregnancy less than a year, the state of hard work, and the hazardous events of women's lifestyles during pregnancy contribute to a significant increase in the risk of premature birth. In addition, short or long duration of sleep and fatigue were associated with an increased risk of premature spontaneous birth.

\section{Recommendations}

Health care providers should focus their efforts on adjusting the lifestyle of maternal at the risk of PTB, for example, appropriate nutrition, and avoiding lifestylethreatening factors (e.g. working or standing on feet for long times, sleep disorders) that will lead to better pregnancy outcomes.

\section{Conflict of Interest}

The authors emphasized that there is no conflict of interest regarding the publication of this research paper.

\section{Sources of Funding}

The author reported that there is no funding source for this study supported by any institution.

Acknowledgements.

The authors would like to thank all the women who participated in this research paper.

\section{Key Point}

\section{Problem}

Preterm delivery is the main problem in obstetrics today; are represent nearly $10 \%$ of all deliveries. It is associated with an increased risk of neonatal mortality, and admission to ICU, as well as high costs.

What is Already Known?

Healthy lifestyle for pregnant women is considered as important preventive measures that are essential for fetal development and reduces the risk of complications, especially in high-risk pregnancies.

What this Paper Adds?

Stresses of heavy work (i.e. hard work, working for long hours, stand for long periods and night work), and serious events in the lifestyle of pregnant women as well as sleep for short or prolonged periods, and vital exhaustion contributed to an increased the risk of spontaneous PTB.

Highlights:

Lifestyle changes for pregnant women at risk of spontaneous preterm delivery through health care providers will lead to healthy pregnancy outcomes.

\section{References}

[1] Rubens, C. E., Sadovsky, Y., Muglia, L., Gravett, M. G., Lackritz, E., \& Gravett, C. (2014). Prevention of preterm birth: harnessing science to address the global epidemic. Science translational medicine, 6 (262), 262sr5-262sr5.

[2] Harrison, M. S., \& Goldenberg, R. L. (2016). Global burden of prematurity. In Seminars in fetal and neonatal medicine, 21 (2): 74-79. WB Saunders. 10.1016/j.siny.2015.12.007.

[3] Zeitlin, Szamotulska, J., K., Drewniak, N., Mohangoo, A. D., Chalmers, J. and Sakkeus, L., (2013). Preterm birth time trends in Europe: a study of 19 countries. BJOG; 120: 1356-65.

[4] Catov, J. M., Bodnar, L. M., Olsen, J., Olsen, S., \& Nohr, E. A. (2011). Periconceptional multivitamin use and risk of preterm or small-for-gestational-age births in the Danish National Birth Cohort-. The American journal of clinical nutrition, 94 (3), 906-912.

[5] Shah, P. S., McDonald, S. D., Barrett, J., Synnes, A., Robson, K., Foster, J.,... \& O'Brien, K. (2018). The Canadian Preterm Birth Network: a study protocol for improving outcomes for preterm infants and their families. CMAJ open, 6 (1), E44.

[6] Cnattingius, S., Villamor, E., Johansson, S., Bonamy, A. K. E., Persson, M., Wikström, A. K., \& Granath, F. (2013). Maternal obesity and risk of preterm delivery. Jama, 309 (22), 23622370 .

[7] Goldenberg, R., L., Gravett, M., G., Iams, J., Papageorghiou, A., T., and Waller, S., A. (2012): The preterm birth syndrome: issues to consider in creating a classification system. Am. J. Obstet. \& Gynecol.; 206 (2): 113-8.

[8] Hamilton, B., Martin, J., and Ventura, S. (2011). Births: Preliminary data for 2010. National Vital Statistics Reports.; 60: 2. Hyattsville, MD: National Center for Health Statistics.

[9] Muglia, L., J. \& Katz, M. (2010): The enigma of spontaneous preterm birth. New England Journal of Medicine; 362 (6): $529-35$.

[10] Newnham, J. P., Dickinson, J. E., Hart, R. J., Pennell, C. E., Arrese, C. A., \& Keelan, J. A. (2014). Strategies to prevent preterm birth. Frontiers in immunology, 5, 584.

[11] Newnham, J. P., Kemp, M. W., White, S. W., Arrese, C. A., Hart, R. J., \& Keelan, J. A. (2017). Applying precision public health to prevent preterm birth. Frontiers in public health, 5, 66.

[12] Frayne, J., \& Hauck, Y. (2017). Enjoying a healthy pregnancy: GPs' essential role in health promotion. Australian family physician, 46 (1/2), 20. 
[13] Lengyel, C. S., Ehrlich, S., Iams, J. D., Muglia, L. J., \& DeFranco, E. A. (2017). Effect of modifiable risk factors on preterm birth: a population based-cohort. Maternal and child health journal, 21 (4), 777-785.

[14] Merialdi, M., \& Requejo, J. H. (2012). Low Birth Weight and Preterm Infants: Causes, Prevalence, and Prevention. In Encyclopedia of Human Nutrition, (3-4): 100-103. Elsevier Inc. DOI: 10.1016/B978-0-12-375083-9.00173-2.

[15] Iyoke, C. A., Lawani, L. O., Ezugwu, E. C., Ilo, K. K., Ilechukwu, G. C., \& Asinobi, I. N. (2015). Maternal risk factors for singleton preterm births and survival at the University of Nigeria Teaching Hospital, Enugu, Nigeria. Nigerian journal of clinical practice, 18 (6), 744-750.

[16] Hossain, A., \& Ahmed, T (2017). Association between gestational weight and inadequate antenatal care visits among third trimester low-income women: A cross-sectional study in Bangladesh. J Pregnancy Reprod 1: DOI: 10.15761/JPR.1000116

[17] Palmer, K. T., Bonzini, M., Harris, E. C., Linaker, C., \& Bonde, J. P. (2013). Work activities and risk of prematurity, low birth weight and pre-eclampsia: an updated review with meta-analysis. Occup Environ Med, 70 (4), 213-222.

[18] Liu, L., Oza, S., Hogan, D., Perin, J., Rudan, I., Lawn, J. E.,... \& Black, R. E. (2015). Global, regional, and national causes of child mortality in 2000-13, with projections to inform post2015 priorities: an updated systematic analysis. The Lancet, 385 (9966), 430-440.

[19] Vahratian, A., Siega-Riz, A. M., Savitz, D. A., \& Thorp Jr, J. M. (2004). Multivitamin use and the risk of preterm birth. American journal of epidemiology, 160 (9), 886-892.

[20] Guendelman, S., Pearl, M., Kosa, J., L., Graham, S., Abrams, B., and Kharrazi, M. (2013): Association between preterm delivery and pre-pregnancy body mass (BMI), exercise and sleep during pregnancy among working women in Southern California. Maternal Child Health J.; 17: 723-31.

[21] Kelman, L., \& Rains, J. C. (2005). Headache and sleep: examination of sleep patterns and complaints in a large clinical sample of migraineurs. Headache: The Journal of Head and Face Pain, 45 (7), 904-910.

[22] Qiu, C., Sixto E. S., Gelaye, E., Daniel A. E., Cande V. A., and Michelle A. W. (2015). Maternal sleep duration and complaints of vital exhaustion during pregnancy is associated with placental abruption. J Matern Fetal Neonatal Med.; 28 (3): 350-355. doi: 10.3109/14767058.2014.916682

[23] Blencowe H, Cousens S, Oestergaard MZ, Chou D, Moller $\mathrm{AB}$, Narwal $\mathrm{R}$, et al. National, regional, and worldwide estimates of preterm birth rates in the year 2010 with time trends since 1990 for selected countries: a systematic analysis and implications. Lancet (2012) 379: 216272.10.1016/S0140-6736 (12) 60820-4 [PubMed] [CrossRef]

[24] Ayman S. A. and Abdelwahid, A. (2015): Rate and risk factors of preterm births in a secondary health care facility in Cairo. World Journal of Medical Sciences; 12 (1): 09-16. DOI: 10.5829/idosi.wjms.2015.12.1.9243.

[25] Liu, F. L., Zhang, Y. M., Parés, G. V., Reidy, K. C., Zhao, W. Z., Zhao, A.,... \& Wang, P. Y. (2015). Nutrient intakes of pregnant women and their associated factors in eight cities of China: a cross-sectional study. Chinese medical journal, 128 (13), 1778.
[26] Passini, R., Jr., Cecatti, J., G., Lajos, G., J., Tedesco, R., P. and Nomura, M. L. (2014): Brazilian multicentre study on preterm birth (EMIP): Prevalence and factors associated with spontaneous preterm birth. PLoS ONE 9 (10): e109069. doi: 10.1371/journal.pone.0109069

[27] Sebayang, S., Dibley, M., Kelly, P., Shanka, A., and Anuraj, H. (2012): Determinants of low birth weight, and small-forgestational-age and preterm birth in Lombok, Indonesia: Analyses of the birth weight cohort of the SUMMIT trial. Tropical Medicine and International Health; 17 (8): 938-950.

[28] Fuchs, F., Monet, B., Ducruet, T., Chaillet, N., \& Audibert, F. (2018). Effect of maternal age on the risk of preterm birth: A large cohort study. PloS one, 13 (1), e0191002.

[29] Oliver, C. E., Agatha, N. D., Chidinma, V. G., Ohwodo, H., David, A. O., and Olufunto, O. K. (2012): Incidence of and socio-biologic risk factors for spontaneous preterm birth in HIV positive Nigerian women. BMC Pregnancy and Childbirth; 12: 93. DOI: 10.1186/1471-2393-12-93

[30] Auger, N., Leduc, L., Naimi, A. I., \& Fraser, W. D. (2016). Delivery at term: impact of university education by week of gestation. Journal of Obstetrics and Gynaecology Canada, 38 (2), 118-124.

[31] Joseph, K. S., Fahey, J., Shankardass, K., Victoria, M. A. O'Campo, P., Dodds, L., Robert, M. L., and Alexander, C. A. (2014): Effects of socioeconomic position and clinical risk factors on spontaneous and iatrogenic preterm birth. BMC Pregnancy Childbirth; 14: 117. doi: 10.1186/1471-2393-14117.

[32] Aragão, V. M. F., Silva, A. A. M., Aragão, L. F., Barbieri, M. A., Bettiol, H., Coimbra, L. C. (2006): Risk factors for preterm births in São Luís, Maranhão, Brasil. Cad SaúdePública; 20: 57-63.

[33] Lutfi, A. S. and Ezat, H., A. (2015): Risk factors of preterm birth among Palestinian women: Case group study. Austin J Nurs Health Care; 2 (1): 1011.

[34] Victor, H. G., Yvette, C. C. and Niki, B. I. (2011): Influence of gestational age and reason for prior preterm birth on rates of recurrent preterm delivery. American Journal of Obstetrics and Gynecology; 205: 275.e1-275.e5.

[35] Abu Hamad, K., H., Abed, Y. and Abu Hamad, B. (2007). Risk factors associated with preterm birth in Gaza strip: Hospital-based case-group study. East Mediterr Health J; 13: 1132-41.

[36] Chen, X., When, S. W., Fleming, N., Demissie, K., Rhoads, G. G. and Walker, M. (2007). Teenage pregnancy and adverse birth outcomes: A large population based retrospective cohort study. International Journal of Epidemiology, 36, 368-373.

[37] Al-Jasmi, F., Al-Mansoor, F., Alsheiba, A., Anne, O. C., Thomas, P. C., Moshaddeque, M., H. (2002): Effect of interpregnancy interval on risk of spontaneous preterm birth in Emirati women United Arab Emirates. Bulletin of the World Health Organization 2002; 80: 871-875.

[38] DeFranco, E. A., Ehrlich, S., and Muglia, L. J. (2014): Influence of interpregnancy interval on birth timing. BJOG; DOI: 10.1111/1471-0528.12891.

[39] Takayama, J. I., \& Matsuo, N. (2010). The enigma of spontaneous preterm birth. The New England journal of medicine, 362 (21), 2032-2033. 
[40] Escribà-Aguir, V., Sandiago, P. H., and Saurel, M. J. (2001). Physical load and psychological demand at work during pregnancy and preterm birth. Int Arch Occup Environ Health; 74: $583-588$.

[41] Traviss, G., Meer, S., West, R., and House, A. (2013): Life events and difficulties and their association with antenatal distress in White and South Asian women in the UK. Soc Psychiatry Psychiatr Epidemiol; 48 (5): 725-734.

[42] Class, Q. A., Lichtenstein, P., Långström, N., \& D'onofrio, B. M. (2011). Timing of prenatal maternal exposure to severe life events and adverse pregnancy outcomes: a population study of 2.6 million pregnancies. Psychosomatic medicine, 73 (3), 234.

[43] Zhu, P., Tao, F., Hao, J., Sun, Y. and Jiang, X. (2010): Prenatal life events stress: Implications for preterm birth and infant birth weight. Am J Obstet Gynecol.; 203 (1): 34. 31-4.

[44] Triunfo, S., \& Lanzone, A. (2015). Impact of maternal under nutrition on obstetric outcomes. Journal of endocrinological investigation, 38 (1), 31-38

[45] Nnam, N. M. (2015). Improving maternal nutrition for better pregnancy outcomes. Proceedings of the Nutrition Society, 74 (4), 454-459

[46] Zhang, Y., P., Liu, X., H., Gao, S., H., Wang J., M., Gu, Y. S. and Zhang, J. Y. (2012): Risk factors for preterm birth in five maternal and child health hospitals in Beijing. PLoS One.; 7 (12): e52780.

[47] De-Regil, L. M., Palacios, C., Lombardo, L. K., \& PeñaRosas, J. P. (2016). Vitamin D supplementation for women during pregnancy. Sao Paulo Medical Journal, 134 (3), 274275 .
[48] Li, Z., Ye, R., Zhang, L., Li, H, Liu 1, J. and Ren, A. (2014): Periconceptional folic acid supplementation and the risk of preterm births in China: A large prospective cohort study. Oxford Journals Medicine \& Health International Journal of Epidemiology; 43 (4): 1132-1139

[49] Wagner, C. L., McNeil, R., Hamilton, S. A., Winkler, J., Cook, R. C., and Warner, G. (2013): A randomized trial of vitamin D supplementation in 2 community health center networks in South Carolina. Am J Obstet Gynecol.; 208 (2): 137.e1-13.

[50] Ramakrishnan, U., Grant, F., Goldenberg, T., Zongrone, A., \& Martorell, R. (2012). Effect of women's nutrition before and during early pregnancy on maternal and infant outcomes: a systematic review. Paediatric and perinatal epidemiology, 26, 285-301.

[51] Sharma, S. K., Nehra, A., Sinha, S., Soneja, M., Sunesh, K., Sreenivas, V., \& Vedita, D. (2016). Sleep disorders in pregnancy and their association with pregnancy outcomes: a prospective observational study. Sleep and Breathing, 20 (1), 87-93.

[52] Kajeepeta, S., Sixto, E., S., Gelaye, B., Qiu, C., Barrios, Y., V., Daniel A., E. and Michelle, A., W. (2014): Sleep duration, vital exhaustion, and odds of spontaneous preterm birth: a case-group study. BMC Pregnancy and Childbirth; 14: 337. http://www.biomedcentral.com/1471-2393/14/337.

[53] Dolatian, M., Mehraban, Z. and Sadeghniat, K. (2014): The effect of impaired sleep on preterm labor. West Indian Medical Journal; 63 (1): 62-7. 